\title{
Stress corrosion cracking and component failure: Causes and prevention
}

\author{
U K CHATTERJEE
}

Department of Metallurgical \& Materials Engineering, Indian Institute of Technology, Kharagpur 721 302, India

\begin{abstract}
The century-old problem of stress corrosion cracking $(\mathrm{SCC})$ in metals and alloys has been reviewed highlighting the metallurgical factors like grain boundary precipitation and grain boundary segregation contributing to the process, the electrochemical aspects of the phenomenon and the current knowledge of the mechanisms which can be broadly classified as dissolution-based and cleavage-based models. The introduction covers some field examples of SCC. SCC test methods and preventive measures for SCC have also been discussed.
\end{abstract}

Keywords. Stress corrosion cracking; SCC tests; grain boundary precipitation, grain boundary segregation; repassivation; dissolution mechanisms; cleavage mechanisms; preventive measures.

\section{Introduction}

Stress corrosion cracking (SCC) may be defined as the delayed failure of alloys by cracking when exposed to certain environments in the presence of a static tensile stress. The importance of a conjoint action of corrosion and stress as well as the nature of stress is reflected in the definition. The stress level at which the failure occurs is well below the stress required for a mechanical failure in the absence of corrosion. Again, corrosion alone in the absence of stress does not produce cracking. The stress can be applied or residual. A compressive stress does not cause stress corrosion cracking, rather it is used to prevent this phenomenon. Environmentally induced crack propagation due to cyclic loading is not stress corrosion cracking, but is defined as corrosion fatigue. Environmentally induced cracking in the presence of stress is also encountered in non-metallic materials, e.g. glass and alumina in water or organic polymers in polar solvents. The discussion in the present paper will, however, be confined to SCC in metallic materials.

The earliest report on SCC is probably the occurrence of 'season cracking' in brass cartridge cases in ammonia-bearing environments in the beginning of the present century. Caustic embrittlement of riveted steel boiler plates is another classical example of SCC encountered in the early steam-driven locomotives. The causes of SCC in this case were the residual stress developed due to riveting operations and sodium 
hydroxide present in these areas. Many alloy-environment combinations leading to SCC were discovered with the passage of time. It was recognized with concern that almost all alloys of engineering interest were susceptible to this type of catastrophic degradation in some environment or other, the only silver lining being that all alloys were not susceptible to SCC in all the environments. It was also noticed that pure metals were immune to SCC in the environments in which their alloys showed ready and rapid cracking. A list of alloy-environment systems exhibiting SCC is presented in table 1.

It should be remembered that the table is not exhaustive; newer combinations and newer environments causing SCC in a particular alloy are being regularly discovered and added to this list. The so-called 'specificity' of the environment with respect to an alloy is no longer true. The immunity of pure metals to SCC is also no longer valid. Nevertheless, still only a small number of corrodents cause SCC in a particular alloy and SCC of a pure metal is still confined to laboratory tests.

Practical examples of SCC in engineering alloys, on the other hand, are abundant and varied. Intensive SCC was observed in a high-pressure autoclave made of 18-8 stainless steel (Fontana \& Greene 1967). The failure in service took place in a matter of hours and was traced to the build up of chloride concentration on the outside surface because of evaporation of the water used for cooling which originally contained only a negligible amount of chloride. Yet another interesting example of SCC was the development of longitudinal cracks in a cold-drawn brass tube which had its origin in the bird droppings that provided the ammonia necessary for corrosion (Barer \& Peters 1970). The occurrence of SCC arising from chloride-contaminated moisture has been reported in high-strength aluminium alloy components in low-flying British military aircraft which led to the ban on the use of the material till a solution was found through cladding of the material with pure aluminium. Carbonate-bicarbonate environments have been identified as the probable cause of cracking in natural gas transmission steel pipe lines (Parkins 1980).

Numerous cases of SCC in chemical process plants and power-generation plants have been reported in the literature. Oxygenated pure or impure high temperature water has caused failures in steam generator shells made of carbon or low-alloy steels (Congleton et al 1985). Extensive failures have taken place in austenitic $18 \mathrm{Mn}-4 \mathrm{Cr}$ steel rotor end-retaining rings in contamination with oxygenated high temperature water (Viswanathan 1982). SCC of austenitic stainless steel pipes caused by the same environment in boiling water reactors (BWR) has cost the world's nuclear power industries as much as 10 billion dollars (Staehle 1990). SCC of nickel based alloy 600 in reducing high temperature water and supercritical steam in pressurized water reactors (PWR) has been reported (Coriou et al 1969). Room temperature cracking of sensitized austenitic stainless steels produced by polythionic acid was first experienced in catalytic reformers used in the petroleum industry (Dravnicks \& Samans 1957). Titanium alloys, so reputed for their excellent corrosion resistance in some of the most aggressive media, are known to fail by SCC ir: many environments including red fuming nitric acid (RFNA), hot molten salts, methanol, liquid dinitrogen tetroxide $\left(\mathrm{N}_{2} \mathrm{O}_{4}\right)$ and salt water (Blackburn et al 1972). Hot salt SCC of titanium alloys was first discovered at fingerprints on creep test specimens (Jackson \& Boyd 1966). Dinitrogen tetroxide is used as an oxidant in rocket engines. Interestingly, SCC in this environment is inhibited by the traces of NO.

Stress corrosion cracking thus affects the performance of metallic components, whether mundane or exotic, in envircnments of diverse chemical nature, some of which 
Table 1. Alloy-environment combinations exhibiting stress corrosion cracking.

\begin{tabular}{|c|c|c|c|}
\hline Alloy & Environment & Alloy & Environment \\
\hline $\begin{array}{l}\text { Aluminium } \\
\text { alloys }\end{array}$ & $\begin{array}{l}\text { Air with water vapour } \\
\text { Potable water } \\
\text { Seawater } \\
\mathrm{NaCl} \text { solutions } \\
\mathrm{NaCl}-\mathrm{H}_{2} \mathrm{O}_{2} \text { solutions }\end{array}$ & $\begin{array}{l}\text { Stainless steels } \\
\text { Austenitic }\end{array}$ & $\begin{array}{l}\text { Hot acid chloride solutions } \\
\mathrm{NaCl}-\mathrm{H}_{2} \mathrm{O}_{2} \text { solutions } \\
\mathrm{NaOH}-\mathrm{H}_{2} \mathrm{~S} \text { solutions } \\
\text { Seawater } \\
\text { Concentrated caustic solutions } \\
\text { Neutral halides- } \mathrm{Br}^{-}, \mathrm{I}^{-}, \mathrm{F}^{-}\end{array}$ \\
\hline \multirow[t]{2}{*}{$\begin{array}{r}\text { Carbon } \\
\text { steels }\end{array}$} & $\begin{array}{l}\text { Caustic } \mathrm{NaOH} \text { solutions } \\
\text { Calcium, ammonium and } \\
\text { sodium nitrate solutions }\end{array}$ & $\begin{array}{l}\text { Austenitic } \\
\text { (sensitized) }\end{array}$ & $\begin{array}{l}\text { Polythionic acids }\left(\mathrm{H}_{2} \mathrm{~S}_{n} \mathrm{O}_{6}\right) \\
\text { Sulphurous acid } \\
\text { Pressurized hot water contain- } \\
\text { ing } 2 \mathrm{ppm} \text { dissolved oxygen }\end{array}$ \\
\hline & $\begin{array}{l}\mathrm{HCN} \text { solutions } \\
\text { Acidified } \mathrm{H}_{2} \mathrm{~S} \text { solutions } \\
\text { Anhydrous liquid ammonia } \\
\text { Carbonate/bicarbonate } \\
\mathrm{CO} / \mathrm{CO}_{2} \text { solutions } \\
\text { Seawater }\end{array}$ & $\begin{array}{l}\text { Ferritic } \\
\text { Martensitic }\end{array}$ & $\begin{array}{l}\mathrm{H}_{2} \mathrm{~S}, \mathrm{NH}_{4} \mathrm{Cl}, \mathrm{NH}_{4} \mathrm{NO}_{3} \text {, } \\
\text { hypochlorite solutions } \\
\text { Caustic } \mathrm{NaOH} \text { solutions }\end{array}$ \\
\hline Copper alloys & $\begin{array}{l}\text { Ammoniacal solutions } \\
\text { Amines } \\
\text { Nitrites }\end{array}$ & $\begin{array}{l}\text { Titanium } \\
\text { alloys }\end{array}$ & $\begin{array}{l}\text { Red fuming nitric acid } \\
\text { Hot salts, molten salts }\end{array}$ \\
\hline Nickel alloys & $\begin{array}{l}\text { Caustic alkaline solutions } \\
\text { High-temperature chloride } \\
\text { solutions } \\
\text { High purity steam } \\
\text { Acioic fluoride solutions }\end{array}$ & & $\begin{array}{l}\mathrm{N}_{2} \mathrm{O}_{4} \\
\text { Metanol halide }\end{array}$ \\
\hline
\end{tabular}

are apparently innocent. No wonder then that the last four decades witnessed a spurt of research activities in this area for an understanding of the phenomenon as well as for its prevention. A commendable review of activities in the period 1965-1990 has been made by Newman \& Proctor (1990).

\section{General features of SCC}

The following features are generally common to SCC:

(1) Pure metals are almost immune to cracking in environments where their alloys crack readily.

(2) The existence of a tensile stress, either applied or present as a residual stress, is essential for the cracking process.

(3) SCC for a given alloy usually occurs more readily in a rather specific environment.

(4) The microscopic appearance of stress corrosion cracks, which are either intergranular or transgranular (figures $1 \& 2$ ), is that of a brittle fracture although the metal itself may still be quite ductile in mechanical test. The brittle nature of fracture is quite evident is SEM fractography (figure 3).

(5) In order for SCC to occur a threshold stress or stress intensity must be exceeded. 
(6) SCC, in general, can be accelerated by the application of anodic currents and can be stopped by the application of cathodic currents showing that the process is, at least partly, electrochemical.

Stress corrosion cracking is a complicated subject. It is an outcome of materialenvironment-stress interaction. Metallurgical and electrochemical factors and also the manner in which a specimen is stressed greatly influence the process. Some of them will be discussed in the subsequent sections. Before that, it will be useful to introduce the various SCC testing methods and the parameters used for ascertaining the susceptibility to SCC.

\section{Testing methods}

The SCC testing methods can be categorized as below.

(1) Constant-strain or constant-deformation tests;

(2) tests on statically loaded smooth samples;

(3) tests on statically loaded precracked samples;

(4) slow strain-rate testing (SSRT).

Constant-strain tests make use of U-bend, C-ring, bent-beam specimens or tensile specimens in a small loading frame with nuts on the threaded ends of the specimen. Although the stress distribution within the specimen cannot be precisely known and the stress conditions are difficult to duplicate from specimen to specimen, U-bend specimens have found wide use in evaluating qualitatively the resistance of various alloys to various solution conditions. Time to failure, $t_{f}$, is the parameter used to measure the resistance to SCC.

Tests on statically loaded smooth samples are usually conducted at various fixed stress levels, and the time to failure is measured. A dead-weight load is hung from one end of the specimen, directly or by means of a lever system. Most of the constant deformation specimens can be adapted to constant load by adding a spring in the device. Figure 4 illustrates the typical results obtained from this type of test. A threshold stress below which the time of failure approaches infinity is encountered in some systems, whereas in other systems it is not observed. Time to failure, $t_{f}$, essentially is made up of two components: the time for crack initiation $\left(t_{i}\right)$, and the time for crack propagation, $t_{p}$, so that,

$$
t_{i}+t_{p}=t_{f}
$$

Different metallurgical and electrochemical variables do affect $t_{f}$, but it is difficult, if not impossible, to ascertain these effects separately on $t_{i}$ and $t_{p}$. In smooth specimens usually $t_{i} \gg t_{p}$, whereas in practical situations a pit or a surface roughness feature acts as an aiready initiated crack and the question of its propagation under different variables assumes more importance. The use of pre-cracked specimens, notched or fatigueprecracked, and the application of linear elastic fracture mechanics (LEFM) technique is stress corrosion crack propagation have evolved as a consequence.

Tests on statically loaded precracked samples are usually conducted with a constant applied load and the velocity of crack propagation, $\mathrm{d} a / \mathrm{d} t$, as a function of stress-intensity factor, $k$, is measured. The value of $k$ is calculated from $k=\sigma C^{1 / 2}$ where $\sigma$ is the applied 


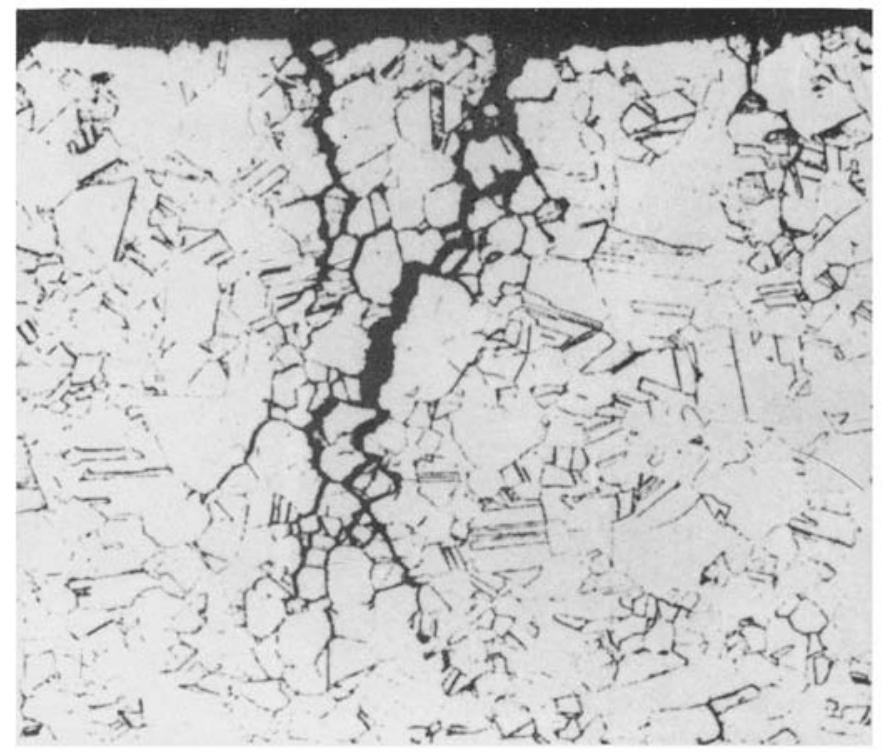

Figure 1. Intergranular stress corrosion cracks in 70-30 brass exposed to ammoniacal solution.

stress and $C$ is the crack length. Figure 5 gives the schematic representation of a typical $\mathrm{d} a / \mathrm{d} t$ versus $k$ plot. Three regions in the plot are identified as stages I, II and IH. No crack propagation is observed below some threshold stress-intensity level, $k_{1 \mathrm{scc}}$. In stage I, the crack-propagation rate increases rapidly with the stress-intensity factor. In

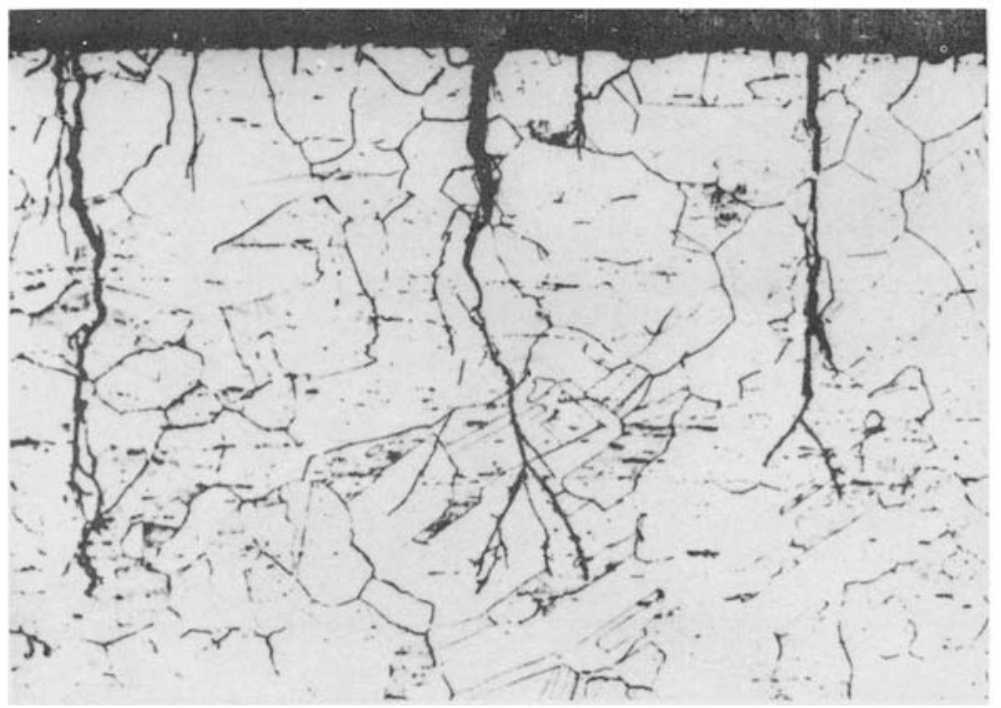

Figure 2. Transgranular stress corrosion cracking in type 304 austenitic stainless steel in boiling $\mathrm{MgCl}_{2}$ solution. 


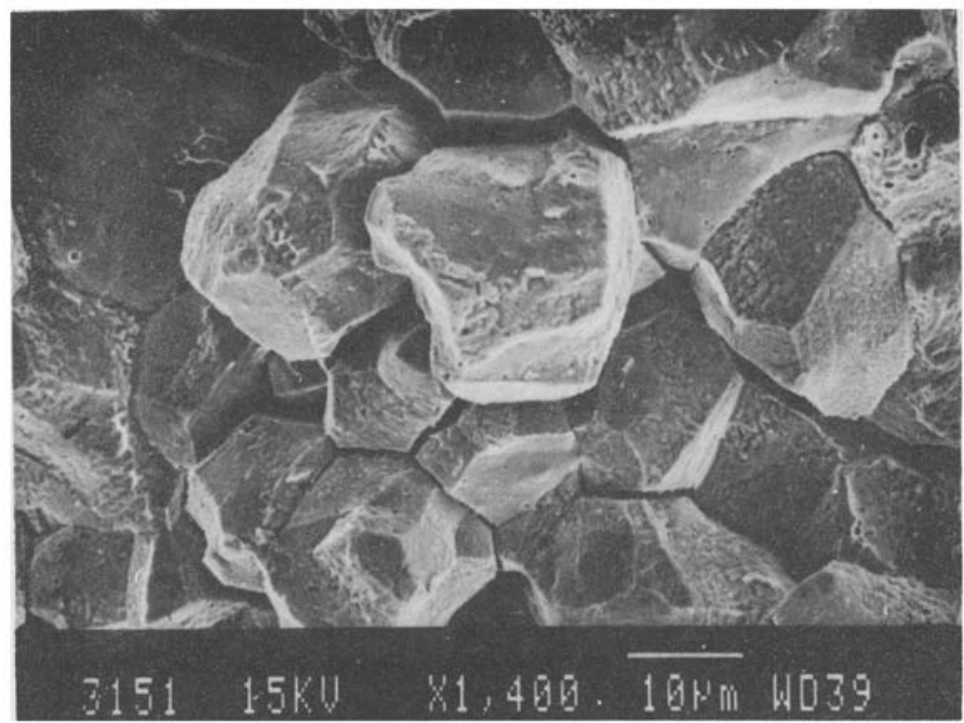

Figure 3. SEM fractograph of intergranular SCC of type 316 stainless steel in polythionic acid showing brittle features.

stage II, the crack-propagation rate approaches some constant velocity, referred to as the plateau velocity, which is characteristic of the alloy/environment combination and is a result of rate-limiting diffusion of the reactant species to the crack tip. The effect of variations in composition, changes is heat treatment, electrochemical variables and changes to the environment get reflected in the plateau velocity and such data become helpful in alloy selection. Alloys which have a low plateau velocity can be chosen in preference to the alloys with a high plateau velocity under the similar conditions of the environment.

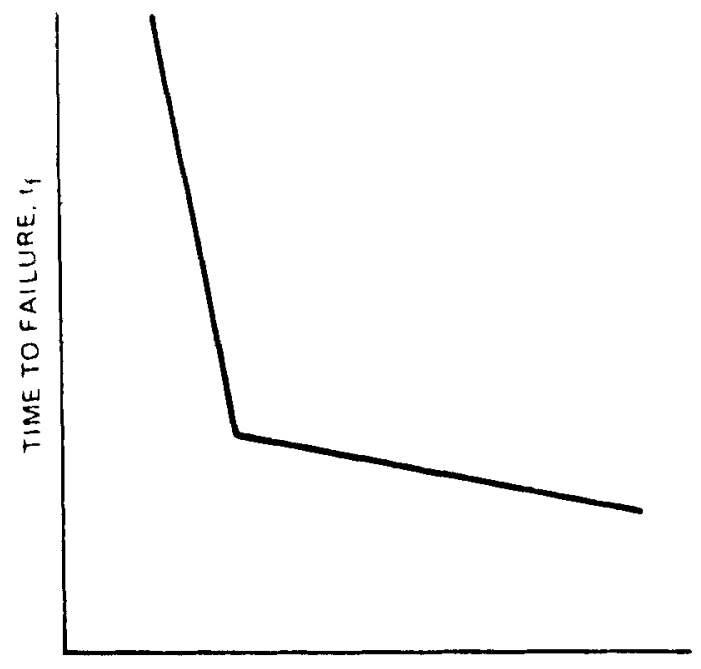

APPLIED STRESS,
Figure 4. Time-to-failure and applied stress relationship obtained in a constant-load type SCC test. 


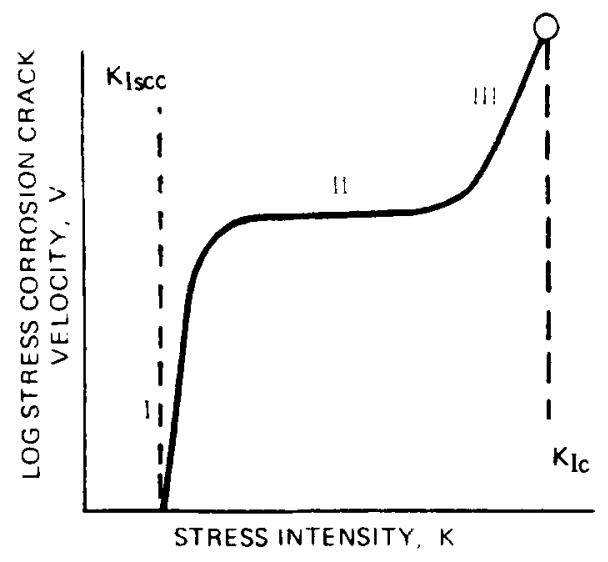

Figure 5. General relationship between stress corrosion crack velocity and stress intensity factor.

The earliest studies involving precracked specimens and LEFM were carried out by Brown \& Beachem [1965] at the US Naval Research Laboratory. They showed that high strength titanium alloys, which were thought to be immune to SCC in dilute aqueous chloride environments on the basis of conventional, smooth specimen stress corrosion tests, were in fact highly susceptible when evaluated using fatigue precracked specimens. Actually, these alloys are resistant to pitting in these environments and stress corrosion crack initiation through pitting does not take place. However, pre-existing flaws and defects make these alloys susceptible to SCC.

Slow strain rate testing is a procedure in which a smooth or a pre-cracked specimen exposed to the corrosive environment is strained at a low crosshead speed $\left(10^{-5}\right.$ to $10^{-9} \mathrm{~m} / \mathrm{s}$ ) to failure. The strain to failure in the corrosive environment and the strain to failure in an inert environment can then be plotted against strain rate, or rather a ratio of these measurements as shown in figure 6. The ratio of other tensile measurements, such as reduction in area and ultimate tensile strength, may be plotted. The plot in figure 6 shows the similar behaviour of the two alloys at high strain rates, the ductility ratio approaching unity, indicating that the failure is through mechanical fracture as SCC crack initiation has not been possible at these high strain rates. Alloy B shows SCC susceptibility in a narrow range of strain rate, higher rate of repassivation of the alloy in the environment resists SCC at slower strain rates. Alloy A shows the behaviour of an alloy which does not repassivate in the environment concerned. The importance of repassivation in SCC will be discussed later.

The slow strain rate technique has the advantage over the constant-strain or constant-load test methods in that the experiment can be completed in a short period of time to ascertain the susceptibility to SCC of an alloy in a given environment. The test conditions, however, are more aggressive than the other methods. So it can be said that an alloy showing resistance in this test should be resistant in service with similar corrosive conditions, but an alloy showing SCC in a slow strain-rate test would not necessarily fail in service, where a forced, continuous strain is absent.

\section{Metallurgical aspects of SCC}

Virtually all alloys are susceptible to SCC in the appropriate environments. The 

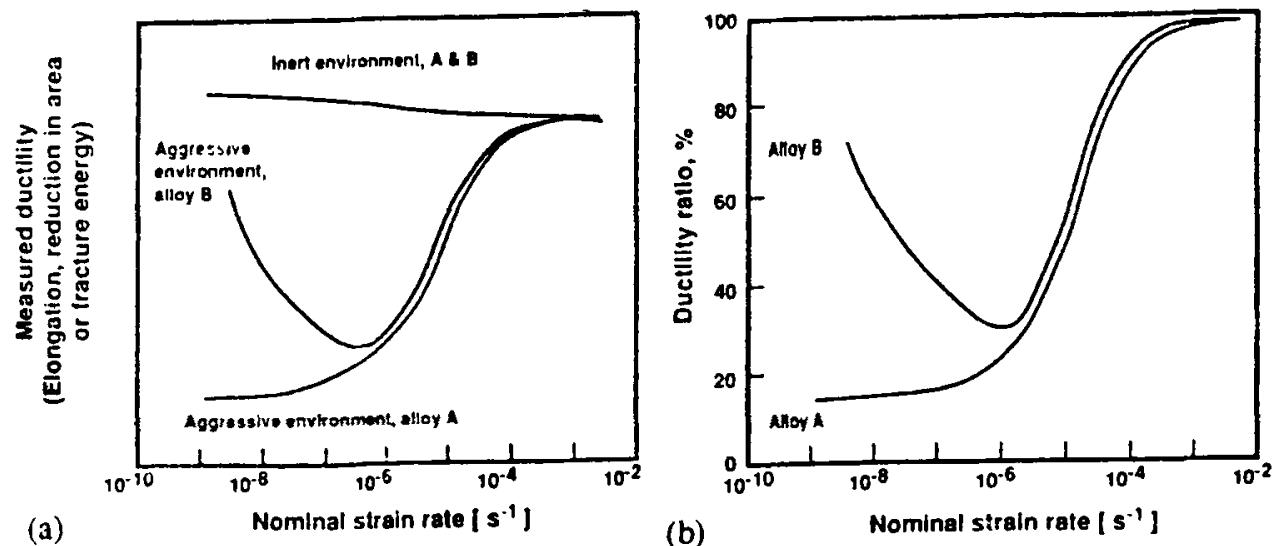

Figure 6. Strain-to-failure plots resulting from slow strain rate testing (a) Schematic of typical ductility versus strain rate behaviour of two different types of alloys tested by the slow-strain-rate technique, (b) schematic of the ductility ratio versus strain-rate behaviour of two different types of alloys. The ductility ratio is the ratio of a ductility measurement such as elongation, reduction in area, or fracture energy measured in the aggressive environment to that obtained in the inert reference environment.

susceptibility to SCC is affected by the chemical composition of the alloy, grain size and preferential orientation of grains, composition and distribution of precipitates, dislocation interactions and the progress of phase transformation. Bulk alloy composition can affect passive-film stability and phase distribution (for example, chromium in stainless steel), minor alloying elements can cause local changes in passive-film forming elements (for example, carbon in stainless steel causing sensitization), impurity elements can segregate to grain boundaries and cause local difference in the corrosion rate (for example, phosphorus in nickel or nickel-base alloys), and inclusions can cause changes in the local crack-tip chemistry as the cracks intersect them (for example, manganese sulphide in steel).

The effect of bulk alloy composition on SCC susceptibility is best exemplified in stainless steels and copper alloys. Figure 7 shows the effect of nickel content on SCC in stainless steels exposed to boiling $42 \%$ magnesium chloride solution, a common SCC medium used in the laboratory to simulate the cracking in hot chloride environments (Copson 1959). The beneficial effect of high nickel content is clearly visible. However, a ferritic stainless steel devoid of nickel, which is generally resistant to SCC in most common service environments that attack austenitic stainless steels, becomes susceptible wilh the addition of 1.5 to $2 \%$ nickel. Duplex stainless steels with high chromium and low nickel content are more resistant to SCC than austenitic stainless steels. Pure copper which is almost immune to SCC in ammoniacal environments becomes readily susceptible with the alloying of $1 \%$ silicon or $0.2 \%$ phosphorus (Thompson \& Tracy 1949). Brasses with a zinc content below $15 \%$ are resistant to SCC. Addition of a third element like $\mathrm{Si}, \mathrm{Al}$, to $70 \mathrm{Cu}-30 \mathrm{Zn}$ brass changes the mode of cracking from intergranular to transgranuiar (Baumann 1962).

Grain-boundary precipitation and grain-boundary segregation play a major role in intergranular stress corrosion cracking. Austenitic stainless steels heated in the temperature range of 500 to $850^{\circ} \mathrm{C}$, develop a chromium-depleted zone along the grain boundary through the precipitation of chromium carbide, a phenomenon known as 


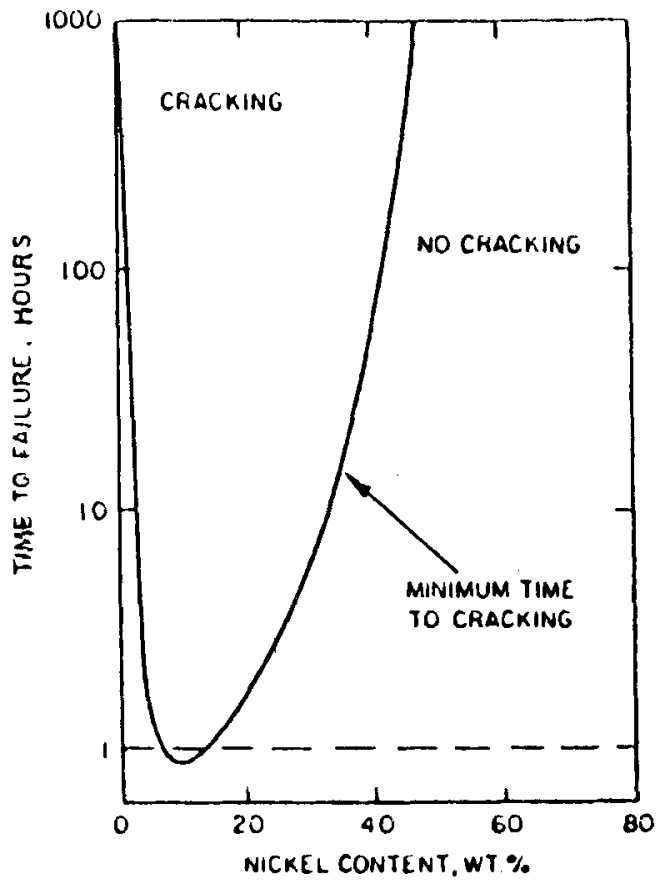

Figure 7. Effect of nickel content on the susceptibility to SCC of stainless steel wires containing $18-20 \%$ chromium in boiling $\mathrm{MgCl}_{2}$ solution.

sensitization. Susceptibility to intergranular SCC and the crack growth rate are related to the degree of sensitization. Intergranular SCC of sensitized austenitic stainless steels is a recurring problem in cooling-water piping of boiling-water nuclear power plants (Gordon 1987). The Ni-Cr-Fe alloy 600 also gets sensitized through chromium depletion at the grain boundary and has been reported to fail by intergranular SCC in high temperature pressurized water (Pessal et al 1979). Grain-boundary precipitation has been identified as a contributing factor in the intergranular SCC of aluminium alloys (Hollingsworth \& Hunsicker 1987). 7000 Series alloys ( $\mathrm{Al}-\mathrm{Zn}-\mathrm{Mg}-\mathrm{Cu}$ ) are most susceptible in the peak-aged condition, the susceptibility is reduced with overaging.

Grain boundary segregation of alloying elements or impurities has been identified as the causative factor of intergranular SCC in many alloys. Grain-boundary enrichment of magnesium in $\mathrm{Al}-\mathrm{Mg}$ alloys accounts for the increased anodic activity or possible formation of magnesium hydride along the grain boundaries (Pow et al 1981; Holroyd \& Scamans 1985). Grain boundary enrichment of impurities such as phosphorus, sulphur, carbon and silicon contributes to the intergranular SCC of iron-base alloys, austenitic stainless steels and nickel-base alloys. The enrichment of impurities in the grain boundaries can be as high as $50 \%$ within a region 1 to $2 \mathrm{~nm}$ thick, facilitating the propagation of a stress corrosion crack along the grain boundary (Jones \& Ricker 1992).

The effect of variation of carbon on the SCC of very low carbon steels were studied (Long \& Uhlig 1965). Carbon segregation at the grain boundary was considered to provide suitable imperfection sites for adsorption of nitrates to promote SCC, and at a very low level of bulk carbon content such segregation was not attainable. Parkins (1969) discussed the role of carbon and/or nitrogen segregation to grain boundaries in SCC of carbon steels and found experimentally that about $0.01 \% \mathrm{C}$ was required to cause SCC in nitrate or caustic environments, which is above the room temperature 
solubility limit. Phosphorus segregation has been shown by several authors to promote intergranular SCC of low alloy steels ( $\mathrm{Cr}-\mathrm{Mo}$ or $\mathrm{Ni}-\mathrm{Cr}-\mathrm{Mo}-\mathrm{V})$ in caustic or water environments at relatively oxidizing potentials (Harrison et al 1977; Burnstein \& Woodward 1983; Bandyopadhpayay \& Briant 1983). Phosphorus segregation has also been identified as a contributory factor in the intergranular SCC of austenitic stainless steels containing less than $0.002 \%$ carbon (Jones 1985) and also in nickel alloy 600 (Guttman et al 1981). Grain-boundary segregation of impurities is deemed responsible for the intergranular SCC of pure iron (Parkins 1990).

In transgranular SCC, alloying effect on slip planarity is a major factor. A number of crack growth models have been proposed based on the planar slip-localized corrosion processes. Planar slip occurs in alloys with low stacking-fault energy, alloys containing ordered phases, or alloys exhibiting short or long range ordering. Addition of nickel to stainless steels (Pickering \& Swann 1963) and manganese to copper (Chatterjee et al 1970) have been reported to develop planar array of dislocations due to the lowering of stacking fault energy and consequently a susceptibility to transgranular SCC. Alloys, on the other hand, are prone to dealloying. It has been suggested that the dealloyed layer acts as a cleavage crack initiator in brass, copper, gold and stainless steels (Sieradzki \& Newman 1987).

\section{Electrochemical aspects of SCC}

A number of environmental parameters influence stress corrosion cracking susceptibility, both in terms of crack initiation and crack growth, as well as the cracking mode in an alloy. Important among these parameters are temperature, nature of solute species and its concentration, $\mathrm{pH}$ and the electrochemical potential. Although the 'specificity' of an environment is no longer valid, still only a few environments can induce SCC in any particular alloy system and the susceptibility varies significantly with potential and $\mathrm{pH}$.

In this pioneering work, Mattsson (1961) showed the dependence of the cracking time of alpha brass on the solution $p \mathrm{H}$. The results were discussed in the background of the potential-pH diagram for $\mathrm{Cu}-\mathrm{H}_{2} \mathrm{O}-\mathrm{NH}_{3}$ system. The formation of an oxide film $\left(\mathrm{Cu}_{2} \mathrm{O}\right)$ and its rupture providing an active dissolution front were thought to be essential requirements for the SCC in this system. The SCC of brass has been shown to be potential dependent (figure 8) with cracking mode changing over from intergranular to transgranular beyond a certain value of applied anodic potential (Sircar et al 1972). For SCC of mild steel in various environments, potential-pH conditions for severe cracking susceptibility have been identified (Congleton et al 1985) which also coincide with the regions of thermodynamically stable protective films (figure 9).

For an inherently reactive metal like mild steel most of the exposed surface will remain inactive if the surface is passivated. Nitrates, hydroxides and carbonates, which are anodic inhibitors of corrosion of carbon steels in appropriate circumstances, have the characteristics of passivating the surface. Along with this inactivity of most of the surface, the environment must also permit the formation of soluble species at the crack tip, so that the dissolution and hence crack propagation can occur. Both these conditions call for a border-line passivity. The ranges of potential within which cracking occurs are therefore expected to coincide with those ranges within which soluble species form. Such ranges are just above the active-passive potential zone in the 


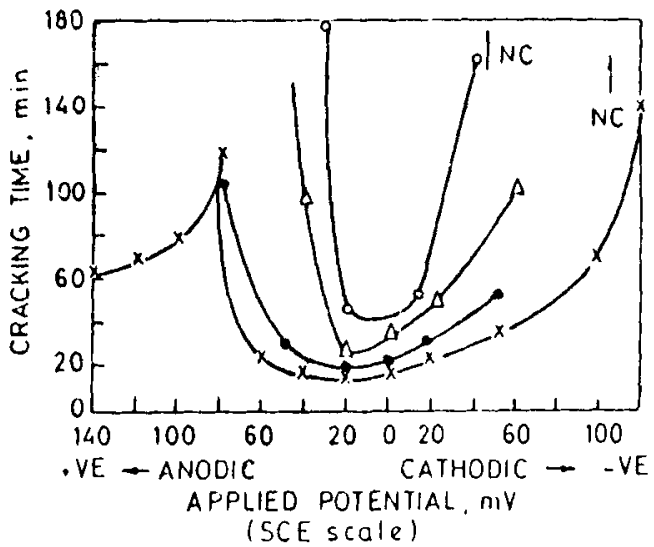

Figure 8. Effect of applied potential on the time-to-fracture of $x$-brass in Mattson's solutions of $\mathrm{pH} 7$ containing $1 \mathrm{~g} \cdot \mathrm{mol} / \mathrm{l}$ $\mathrm{NH}_{4}^{+}$and different compositions of dissolved copper.

anodic polarisation curves. For austenitic stainless steels in chloride media the transgranular SCC takes place at potentials around the breakdown potential and the crack initiation is usually associated with pit formation. These ranges are shown schematically in figure 10 .

The effects of additions in causing the free corrosion potential to move in relation to the potential range for cracking have considerable practical singificance. The addition of small amounts of nitrates to concentrated $\mathrm{NaOH}$ causes the free corrosion potential to become significantly more positive than the cracking potential in alkali, and failure is no longer observed. The free corrosion potential of some mild steels is likely to be at the boundary of cracking range in hydroxide so that the stress corrosion does not occur. The addition of a small amount of iead oxicie causes the free corrosion potential to move into the cracking range and the failure then occurs readily at these potentials. The potential and $\mathrm{pH}$ conditions inside the crack are not the same as those in the bulk of the

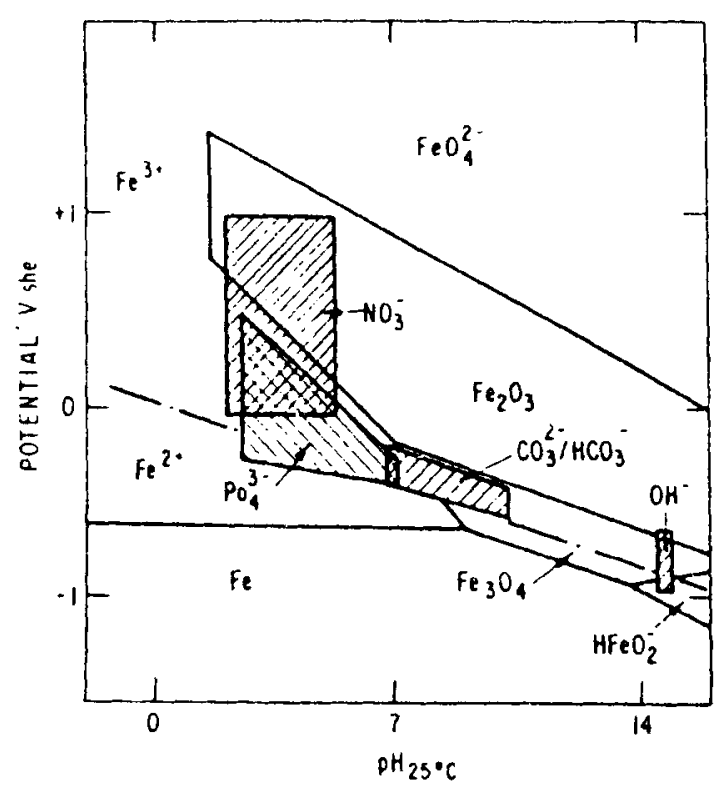

Figure 9. Relationship between $p \mathrm{H} /$ potential conditions for severe cracking susceptibility of mild steel in various environments and the stability regions for solid and dissolved species on the potential-pH diagram. Note that severe susceptibility is encountered where a protective film (phosphate, mixed carbonate, magnetite etc.) is thermodynamically stable, but if ruptured, a soluble species $\left(\mathrm{Fe}^{2+}, \mathrm{HFeO}_{2}\right)$ is metastable. 


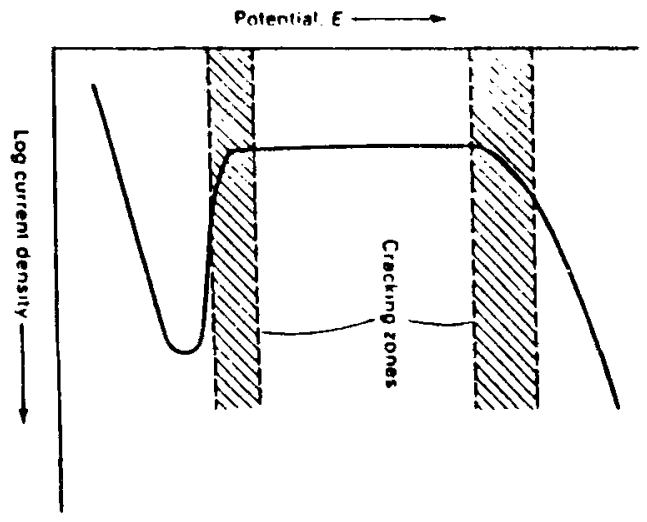

Figure 10. Schematic anodic polarization curve showing zones of susceptibility to stress corrosion cracking.

solution or at the surface of the alloy and so a correlation may not always be possible with the potential- $p \mathrm{H}$ didgram. However, it is reasonable to believe that the conditions prevailing inside the crack essentially meet electrochemical requirements as presented above for the SCC to occur.

If the mechanism whereby stress corrosion crack propagation involves dissolution at the crack tip, then crack velocities may be expected to be related through Faraday's law to the current density at the crack tip according to the equation,

$$
v=i_{a} M / z F \rho
$$

where, $i_{a}$ is the current density, $M$ is the molecular mass of the material, $z$ is the valency of the solvated ions, $F$ is Faraday's constant and $\rho$ is the density of the metal. Taking the effective current density as the largest difference between fast and slow sweep rate polarisation curves, or the maximum current densities observed in scarping or straining electrode experiments at appropriate potentials, a plot of these current densities against calculated crack velocities for a variety of stress corrosion systems yields a straight line (Parkins 1979). There is good correlation in some cases whereby the mechanism postulating initiation and propagation of cracks through dissolution is collaborated. The deviation can be accounted for by attributing the role of dissolution in the crack initiation only, triggering a mechanical fracture propagation step.

'Specificity' of environment also can be explained from the electrochemical standpoint. In very general terms, it is clear that potent solutions will need to promote a critical balance between activity and passivity, since a highly active condition will result in general corrosion or pitting, while a completely passive condition cannot, by definition, lead to stress corrosion. Whilst the relative inactivity of all exposed surfaces except the crack tip may be derived from a noble metal film in the case of alloys containing sufficiently noble elements, for the great majority of engineering alloys inactivity at exposed surfaces is the result of the presence of oxide films overlaying metal surfaces. It is not surprising therefore to find that the alloys of high inherent corrosion resistance (such as those based upon aluminium or titanium, or the austenitic stainless steels, that readily develop protective films) require an aggressive ion, such as a halide to promote stress corrosion cracking. On the other hand, to crack the metals of low inherent corrosion resistance, such as carbon steels or magnesium base alloys, we require the presence of an environment that is itself partially passivating. Thus, carbon steels can be made to fail in solutions of anodic inhibitors, such as hydroxides or 
carbonates, and the cracking of magnesium-base alloys is achieved with an appropriate mixture of $\mathrm{CrO}_{4}^{2-}$ and $\mathrm{Cl}^{-}$ions, but not with either of these species alone.

\section{Mechanisms of SCC}

Any mechanism of stress corrosion cracking should explain the charateristic features of the process, viz. the susceptibility of an alloy in a limited number of environments, the role of stress and the nature of cracking apart from the influence of various metallurgical and environmental factors in the cracking process. Since stress corrosion cracking essentially involves a corrosive environment, mechanisms based on localized dissolution of metal have been postulated. On the other hand, the essential brittle fracture feature of stress corrosion cracking has led to the postulation of mechanism based on cleavage. There are several variations of these two basic mechanisms. According to some models, the so-called continuous electrochemical mechanisms, the initiation and propagation of cracks are both dissolution-controlled. According to the periodic electrochemical-mechanical mechanism, the initiation of cracks or the embrittlement of the region ahead of the crack tip has been dissolution controlled while the propagation is a mechanical brittle fracture step. There is a third group, where the role of dissolution is de-emphasized in the embrittlement process.

\subsection{Dissolution mechanisms}

According to this mechanism a crack advances by preferential dissolution at its tip. The restriction of the dissolution process at the crack tip has been attributed to either a pre-existing active path or to strain-generated active path.

The pre-existing active path mechanism: This is the oldest mechanism proposed (Dix 1940). Grain-boundary segregation or precipitation, as discussed in the previous section, brings about substantial change in the microchemistry of the grain boundary with respect to the bulk alloy. These segregated solutes or precipitated phases may act as anode in the local cell or, by acting as an efficient cathode, may cause the dissolution to be localized upon the immediately adjacent matrix. The role of stress here is to keep the crack open for the accessibility of the corrosive medium to the crack tip. The stress concentration at the crack tip producing yielding has also been considered to accelerate dissolution due to the so 'called 'mechanochemical effect' (Hoar \& West 1962). Intergranular stress corrosion cracking (IGSCC) of sensitized stainless steel in various environments, including high purity water, of carbon steels exposed to nitrate, hydroxide or carbonate-bicarbonate solutions and of aluminium alloys exposed to chloride solutions have been explained in these terms. However, a propensity for intergranular corrosion is no guarantee for IGSCC. It has been shown that though the nickel-base superalloy IN718 and Ticolloy show intergranular corrosion in $\mathrm{NaCl}$ solution, in deaerated solutions they may crack transgranularly (Wang et al 1992).

Strain-generated active path mechanism: The SCC in alloys which do not have a preexisting path has been explained by dissolution of strain-generated active path and there are two distinct models: the film-rupture model (Logan 1952) and the slip-step dissolution model (Vermilyea 1969). According to the film-rupture model, the stress 
opens up the crack and the localized plastic deformation at the crack tip ruptures the passivating film, exposing the bare metal which dissolves rapidly, resulting in crack extension. The crack tip remains bare if the rate of film rupture at the crack tip exceeds the rate of repassivation. If the situation is reverse, the crack tip repassivates completely and is periodically ruptured by the emergence of slip steps and the bare slip-step sustains dissolution till the next repassivation.

Since many of the stress corroding systems are associated with film formation and the SCC occurs under some sort of borderline passivity condition (discussed earlier), most investigators now agree that film rupture is essential to initiate cracking. The emerging slip-steps at the surface as a result of deformation also provide an explanation for transgranular crack initiation. However, controversy persists in regard of a crack propagation by continued dissolution. For example, transgranular cracking would be expected to grow on the active slip plane, where deformation would cause continual film rupture, contrary to the experimental fact that cracks grow on planes of the type $\{100\}$ or $\{110\}$ (Liu et al 1980). Also, a crack growing by electrochemical dissolution at unfilmed crack tip should leave a relatively smooth, featureless surface, but crystallographic cleavage, often with arrest marks (for transgranular SCC), and well-defined grain boundary (for intergranular SCC) features are often present on fracture surfaces. Although the slip-step dissolution model accounts for the presence of arrest marks, it fails to account for the matching opposite fracture surfaces.

A corrosion tunnel model (Swann \& Pickering 1963) has emerged where dissolution and mechanical fracture have been combined. It assumes that a fine array of small corrosion tunnels form at the emerging slip steps. These tunnels grow in diameter and length until the stress in the remaining ligaments causes ductile deformation and fracture. However, such a model should produce grooved fracture surface with evidence of microvoid coalescence at the broken ligaments, which have not been observed experimentally. So this model has been modified subsequently (Silcock $\&$ Swann 1979) by suggesting that the application of a tensile stress results in a change in the morphology of corrosion damage from tunnels to thin, flat slots. The width of the corrosion slots approach atomic dimensions and a close correspondence of matching surfaces is expected.

\subsection{Cleavage mechanisms}

Several mechanisms have been postulated to explain the cleavage type cracking encountered in SCC. These are: hydrogen-assisted cracking, tarnish-rupture, film induced cleavage, adsorption induced cleavage and atomic surface mobility mechanisms.

Hydrogen assisted cracking is very often described by the decohesion model in which atomically dissolved hydrogen acts to weaken the interatomic bonds in the plain-strain region of the crack tip by lowering the surface energy $\gamma_{s}$ in the Griffith equation,

$$
\sigma_{c}=\left(2 E \gamma_{s} / \pi c\right)^{1 / 2},
$$

where $\sigma_{c}$ is the fracture stress necessary to cause the propagation of an elliptical crack of length $2 c$ and $E$ is the Young's modulus. Blocked glide planes have been considered to provide the initial Griffith cracks (Petch \& Stables 1952). It has also been suggested (Jani et al 1990) that hydrogen decreases the stacking fault energy to induce coplanar deformation at the tip. Embrittlement would then result from Lomer-Cottrell supersessile 
dislocations on the intersecting slip planes. A somewhat similar model has been presented to explain the hydrogen assisted cracking in $\mathrm{Fe}-3 \mathrm{Si}$ single crystals and the observed crack arrest marks (Chen \& Gerberich 1991). The embrittlement of $\mathrm{Nb}, \mathrm{Ta}$, $\mathrm{Ti}, \mathrm{V}$ and $\mathrm{Zr}$ is due to the stress-assisted formation of brittle hydride phase ahead of the crack tip which facilitates crack growth by cleavage, with cracks arresting at the boundary where the relatively tough matrix is encountered. Another particle of hydride then forms in the region of crack tip and the process is repeated, resulting in discontinuous crack growth.

Hydrogen assisted crack growth in the manner described has been suggested as the SCC mechanism for ferritic steels, nickel base alloys, austenitic stainless steels, aluminium alloys and intermetallic compounds. The most probable source for atomic hydrogen to enter into the metal is the cathodic reduction of hydrogen ions accom-panying the anodic dissolution in the aqueous environments. Materials with impurities like sulphur, phosphorus, antimony and tin segregated at grain boundaries have been found to be more susceptible to hydrogen-induced cracking, because these impurities act as hydrogen-evolution poisons (Latanision \& Opperhauser 1974). On the other hand, the growing stress corrosion cracks have been stopped effectively in low-strength ductile alloys by cathodic polarisation, refuting the validity of hydrogen-assisted SCC in these alloys. Again, all the environments and conditions under which SCC is encountered do not produce hydrogen and some of them produce surface films which constitute an effective barrier to hydrogen entry (Hardie 1990). These restrict the universal applicability of hydrogen-induced cracking as SCC mechanism.

The adsorption-induced cleavage mechanism or the stress-sorption cracking mechanism (Uhlig 1959) is based on the hypothesis that adsorption of environmental species lowers the interatomic bond strength and the stress required for cleavage fracture, an idea similar to the decohesion model of hydrogen-induced cracking. Adsorption is assumed to be potential dependent which accounts for the stoppage of SCC by cathodic polarisation below a critical potential. The specificity of the species for inducing SCC in a particular alloy can also be conveniently explained in terms of preferential adsorption. However, this model does not explain how the crack maintains an atomically sharp tip in a normally ductile material and it also fails to explain the discontinuous nature of crack propagation (Parkins 1990).

The tarnish-rupture mechanism was originally proposed to explain discontinuous transgranular crack growth of $\alpha$-brass single crystals in ammoniacal solutions (Edeleanu \& Forty 1960; Forty \& Humble 1963). According to this model, a brittle surface film or tranish forms on the metal which fractures under the applied stress. The exposed bare metal reacts rapidly with the environment, the film grows again and the cycle of growth and fracture of the tarnish is repeated. The model was modified subsequently (McEvily \& Bond 1965; Beavers et al 1972) for intergranular SCC proposing that the tarnish penetrates along the grain boundary ahead of the crack tip. At present, experimental results are insufficient to confirm or refute this mechanism, though some workers (Pinchback et ai 1976) have questioned the validity of grainboundary penetration in all systems.

The film-induced cleavage mechanism developed as a consequence of the tarnishrupture model (Pugh 1985; Sieradzki \& Newman 1985). In this model it is assumed that 
dissolution leads to the formation of a surface film and a crack growing in the film propagates further into the underlying metal. From an initial arrest position, the crack advances by cleavage for a limited distance, after which the crack becomes progressively blunted by plastic deformation until the propagation stage is repeated.The film may be a dealloyed layer or oxide, in which nanoporosity is considered to be the key feature leading to the injection of a sharp crack into the substrate. Experimental results showing the correlation of SCC with dealloying have been given for $\mathrm{Cu}-\mathrm{Zn}$ and $\mathrm{Cu}-\mathrm{Al}$ alloys (Sieradzki et al 1987), and also for stainless steel (Newman et al 1989). Certain objections have been put forward against this mechanism. The crack advance distance as measured from arrest marks is typically of the order of a few micrometers and doubts have been raised (Gerberich \& Chen 1990) as to whether a cleavage crack could penetrate that far from an initiating film that is only of the order of $30 \mathrm{~nm}$ thick. Dealloyed layers are also unlikely to have sufficient adhesion to the substrate or inherent brittleness to sustain cracking.

The atomic surface mobility mechanism (Galvele 1987) suggests that many forms of environmentally induced cracking, including hydrogen embrittlement, SCC and liquid-metal embrittlement, grow by the capture of surface vacancies at the crack tip and counter-current surface diffusion of atoms away from the crack tip. The coefficient of surface self-diffusion will dominate the crack growth rate and the role of the environment is to change that diffusivity which is directly related with the presence of low melting surface compounds. However, it has been pointed out (Parkins 1990) that although carbon steel cracks in nitrates which form low-melting compounds with iron, it also cracks in the presence of high melting point $\mathrm{Fe}_{3} \mathrm{O}_{4}$. Oriani (1990) puts an opposite viewpoint by suggesting that the flux of atoms in the region of a stressed crack tip should be the reverse of what the mechanism requires, by analogy with diffusional creep. It has been criticized (Newman \& Procter 1990) that many of the correlations postulated in this mechanism would work equally well if the criterion was surface energy reduction, rather than increase in diffusivity, and thus it becomes indistinguishable from earlier surface energy models.

The proposed mechanisms of SCC thus differ immensely from one another; some suggesting an exclusive role of dissolution while some others giving dissolution a marginal or no role at all in the cracking process. While the proponents of a particular mechanism have produced enough evidence in support of the mechanism, observations not conforming to the mechanism have also been cited in plenty. Though there have been attempts from time to time to find a unified theory explaining all features of SCC in all the alloy-environment systems, it appears more reasonable to believe that the mechanism varies from system to system. It is also probable that no particular mechanism operates exclusively in one system but that more than one mechanism is at play. Decades ago, Parkins (1976) proposed that the different mechanisms of stress corrosion should be considered as occurring within a continuous spectrum, with a gradual transition from one to the other as the dominance of corrosive processes is replaced by stress or strain leading to a brittle fracture (table 2). The picture appears to have remained unchanged.

\section{Preventive measures}

Control of stress: Lowering of applied stress below threshold stress or stress intensity by suitable changes in design and lowering or removal of residual stress by annealing 


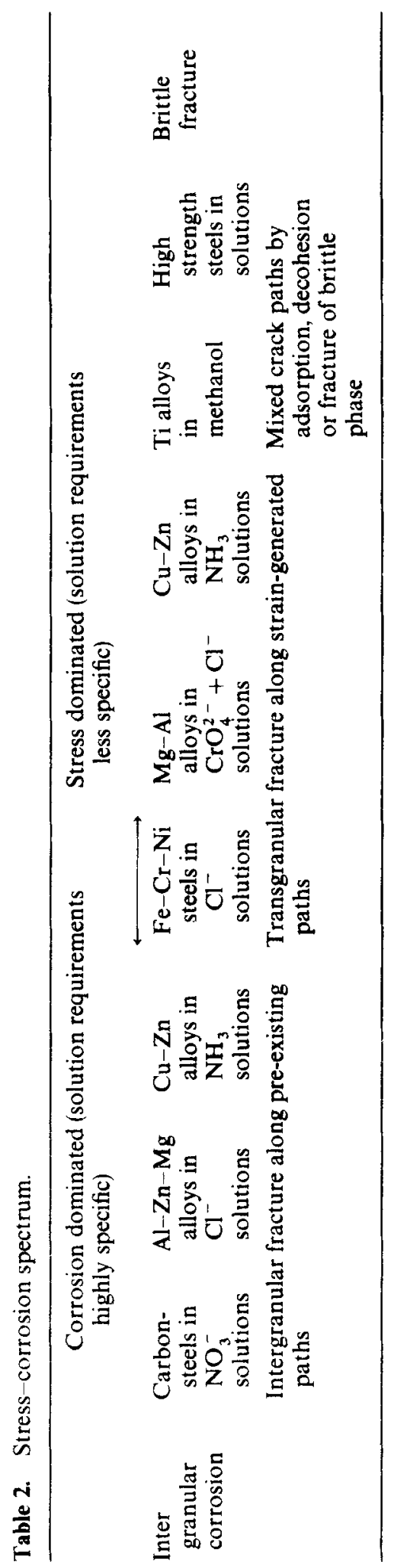


treatment are effective means to reduce the incidence of SCC in service. The seasonal cracking of brass cartridge cases was prevented by proper stress relief annealing treatment. It is recommended practice to give such a treatment to brass tubes after drawing or to steel tubes after welding for use in sour oil wells. However, annealing may be impractical for some stainless steels which sensitize and become susceptible to intergranular attack.

Since a tensile component of stress is required in SCC, it can be prevented by putting the surface of a component into compression, e.g. by shot-peening. The treatment needs to be applied uniformly. It will not be effective if pitting occurs on the compressive layer.

Control of corrosion: The elimination or reduction of the damaging species is desirable, but often difficult to achieve in practice. The initial non-damaging concentration of the species may become high in the crevices or under high temperature conditions bringing about failures. However, the prevention of intergranular SCC of sensitized stainless steel, a recurring and expensive problem in cooling-water piping of boiling water nuclear power plants, has been achieved by minimizing both dissolved oxygen and chloride (Williams 1959).

Use of inhibitors reduces or even eliminates SCC, possibly by moving the corrosion potential outside the range of cracking. The addition of small amounts of nitrates to concentrated $\mathrm{NaOH}$ prevents $\mathrm{SCC}$ of steel, as discussed in section 4. Substances like $\mathrm{H}_{3} \mathrm{PO}_{2}, \mathrm{Na}_{2} \mathrm{O}_{4}$ and $\mathrm{CO}\left(\mathrm{NH}_{2}\right)_{2}$, which may be expected to form insoluble products with iron, retard or prevent cracking in nitrates. Addition of traces of $\mathrm{NO}$ to $\mathrm{N}_{2} \mathrm{O}_{4}$ or $1-2 \% \mathrm{H}_{2} \mathrm{O}$ to RFNA or $\mathrm{CH}_{3} \mathrm{OH} / \mathrm{HCl}$ mixtures prevent $\mathrm{SCC}$ of titanium alloys in these media (Blackburn et al 1972). The addition of water causes anodic inhibition by shifting the potential to the safe passive potential range. However, there are some practical limitations for the use of inhibitors. Many failures occur in steam or under condensation conditions, and in both these cases the transport of inhibitors to sites of crack initiation is not feasible.

Increasing the corrosion rate to reduce SCC might appear to be a ridiculous propositon. But since SCC is a form of highly localized corrosion, extending corrosion over the whole of the surface will usually lessen the probability of such failures. This approach is unlikely ever to be a permanent remedy. It is employed in making up mixtures containing $\mathrm{HCl}$ to clean austenitic stainless steel parts in chemical plants, the corrosion rate is maintained $>10$ mpy (Laque \& Copson 1965).

Electrochemical protection: Cathodic protection will control SCC in alloys which crack by anodic dissolution mechanism, but is likely to accelerate hydrogen-induced cracking, particularly in high strength alloys. SCC failure of $\mathrm{Kraft}$ continuous digesters in pulp and paper industry in $\mathrm{NaOH}-\mathrm{Na}_{2} \mathrm{~S}$ environment at $140^{\circ} \mathrm{C}$ has been reported (Singbell \& Garner 1987) to have been mitigated by the application of anodic protection.

Material selection: Choosing a different alloy resistant to the particular environment is a popular option to prevent SCC. An alloy having the lowest plateau velocity, as discussed in section 3, can be chosen from among a number of susceptible alloys. Mitigation of SCC by alloy development has been a rare endeavour. However, it is reported (Newman \& Procter 1990) that a relatively inexpensive stainless steel has been 
developed by Japanese workers which resists SCC up to $140^{\circ} \mathrm{C}$ in crevice tests with $20 \% \mathrm{NaCl}$ in which 304 stainless steel will fail at $60^{\circ} \mathrm{C}$. The addition of copper raises the lower critical potential for SCC. Minimisation of phosphorus content in austenitic stainless steels is also a key approach to make them resistant to chloride induced SCC.

The cladding of high strength aluminium alloys with pure aluminium to mitigate SCC in aircraft components has been mentioned in $\S 1$. The relatively low susceptibility of pure metals to SCC has been utilized in this preventive measure.

Liberal help has been taken from the review articles of Scully (1979), Newman \& Procter (1990), Parkins (1992), Jones \& Ricker (1992) and the text book by Jones (1992) in the preparation of this article.

\section{References*}

Bandyopadhyay N, Briant C L 1983 Metall. Trans. A14: 2005

Barer R D, Peters B F 1970 Why metals fail (New York: Gordon and Beach) 6: 177

Baumann G 1962 The Brown Boveri Review 49: 323

Beavers J A, Rosenberg J C, Pugh E N 1972 In Proc. 1972 Tri-Science Conf. Corrosion, MCIC 73-19 (Metals and Ceramic Infomation Center) p. 57

Blackburn M J, Smynl W H, Feeney J A 1972 In Stress corrosion cracking in high strength steels and titanium and aluminium alloys (ed.) B F Brown (Washington DC: Naval Research Lab.)

Brown B F, Beachem C D 1965 Corros. Sci. 5: 745

Burnstein G T, Woodward J 1983 Metall. Sci. 17: 111

Chatterjee U K, Sircar S C, Banerjee T 1970 Corrosion 26: 141

Chen X, Gerberich W W 1991 Metall. Trans. A22: 59

Congleton J, Shoji T, Parkins R N 1985 Corros. Sci. 25: 633

Copson H R 1959 In Physical metallurgy of stress corrosion fracture (ed.) T N Rhodin (New York: Interscience) p. 247

Coriou H, Grall L, Olivier P, Willermoz H 1969 In Fundamental aspects of stress corrosion cracking (eds) R W Staehle, A J Forty, D Van Rooyen (Houston, TX: NACE) p. 352

Dix E H 1940 Trans. Am. Inst. Min. Metall. Eng. 137: 11

Dravnicks A, Samans C H 1957 Proc. Am. Petroleum Inst. 37: 100

Edeleanu C, Forty A J 1960 Philos Mag. 5: 1029-1040

Fontana M G, Greene N D 1967 Corrosion engineering (New York: McGraw Hill) 3: 102

Forty A J, Humble P 1963 Philos. Mag. 8: 247

Galvele R 1987 Corros. Sci. 27: 1

Gerberich W W, Chen S 1990 In Environment-induced fracture of metals (eds) R P Gangloff, $M$ B Ives (Houston, TX: NACE) p. 167

Gordon B M 1987 In Metals handbook 9th edn (Metals Park, OH: ASM Int.) 13: 590

Guttmann M, Dumonlin P, Tan Tai N, Fontaie P 1981 Corrosion 37: 416

Hardie D 1990 In Environment-induced fracture of metals (eds) R P Gangloff, M B Ives (Houston, TX: NACE) p. 347

Harrison R P, Jones D De G, Newman F G 1977 In Stress corrosion cracking and hydrogen embrittlement of iron-base alloys (eds) R W Staehle, J Hochman, R D McCright. J E Slater (Houston, TX: NACE) p. 659

Hoar T P, West J M 1962 Proc. R. Soc. A268: 304

Hollingswoth E H, Hunsicker H Y 1987 In Metals handbook 9th edn (Metals Park, OH: ASM Int.) 13: 590

\footnotetext{
*These references are not in our usual format. Readers may please bear with us
} 
Holroyd N J H, Scamans G M 1985 Scr. Metall. 19: 915

Jackson J D, Boyd W K 1966 DMIC technical note (Columbus: Battelle Memorial Institute)

Jani S C, Marek M, Hochman R E, Meletis C I 1990 In Environment-induced fracture of metals (eds) R P Gangloff, M B Ives (Houston, TX: NACE) p. 541

Jones D A 1992 Principles and prevention of corrosion (New York: Macmillan)

Jones R H 1985 In Proc. Int. Symp. Environmental Degradation of Materials in Nuclear Power System-Water Reactors (Am. Nucl. Soc.) p. 173

Jones R H, Ricker R E 1992 In Stress corrosion cracking: Materials performance and evaluation (ed.) R H Jones (Metals Park, OH: ASM Int.) 1: 20

Laque F L, Cospon H R 1963 In The corrosion resistance of metals and alloys (New York: Reinhold) p. 392

Latanision R M, Opperhauser H 1974 Metall. Trans. 5: 483

Liu R, Narita N, Alstetter C, Birnbaum H, Pugh E N 1980 Metall. Trans. A11: 1563

Logan H L 1952 J. Res. Natl. Bur. Stand. 48: 99

Long L M, Uhlig H H 1965 J. Electrochem. Soc. 112: 964

Mattson E 1961 Electrochim. Acta 3: 279

McEvily A J, Bond P A 1965 J. Electrochem. Soc. 112: 141

Newman R C, Corderman R R, Sieradzki K 1989 Br. Corros. J. 24: 143

Newman R C, Procter R P M 1990 Br. Corros. J. 25: 259

Oriani R A 1990 In Environment-induced fracture of metals (eds) R P Gangloff, M B Ives (Houston, TX: NACE) p. 263

Parkins R N 1969 In Fundamental aspects of stress corrosion cracking (eds) R W Staehle, A J Forty, D Van Rooyen (Houston, TX: NACE) p. 361

Parkins R N 1976 In Corrosion (ed.) L L Shreir (London: Newnes-Butterworths) vol. 1, chap. 8, p. 24

Parkins R N 1979 Br. Corros. J. 14: 5

Parkins R N 1980 Br. Corros. Sci. 20: 147

Parkins R N 1990 In Environment-induced fracture of metals (eds) R P Gangloff, M B Ives (Houston, TX: NACE) p. 1

Parkins R N 1992 J. Metall. 44: 12

Pessal N, Airey G P, Lingenfelter B P 1979 Corrosion 35: 100

Petch N J, Stables P 1952 Nature (London) 169: 842

Pickering H W, Swann P R 1963 Corrosion 26: 45

Pinchback T R, Clough S P, Heldt L A 1976 Metall. Trans. A7: 1241

Pow E C, Gerberich W W, Toth L E 1981 Scr. Metall. 15: 55

Pugh E N 1985 Corrosion 41: 517

Scully J C 1979 In Corrosion chemistry (American Chemical Society) p. 321

Sieradzki K, Newman R C 1985 Philos. Mag. 51: 95

Sieradzki K, Kim J S, Cole A T, Newman R C 1987 J. Phys. Chem. Solids 48: 1101

Sieradzki K, Newman R C 1987 J. Phys. Chem. Solids 48: 1101

Silcock J M, Swann P R 1979 In Environment-sensitive fracture of engineering materials (ed.) Z A Foroulis (The Metallurgical Society) p. 33

Singbell D, Garner A 1987 Mater. Perform. 26: 31

Sircar S C, Chatterjee U K, Zamin M, Vijayendra H G 1972 Corros. Sci. 12: 217

Staehle R W 1990 In Environment-induced fracture of metals (eds) R P Gangloff, M B Ives (Houston, TX: NACE) p. 561

Swann P R, Pickering H W 1963 Corrosion 19: $102 t$

Thompson D H, Tracy A W 1949 Trans. Am. Inst. Mech. Eng. 185: 100

Uhlig H H 1959 In Physical metallurgy of stress corrosion fracture (ed.) T N Rhodin (New York: Interscience) p. 1

Vermilyea D A 1969 Fundamental aspects of stress corrosion cracking (eds) R W Staehle, A J Forty, D Van Rooyen (Houston, TX: NACE) p. 15

Viswanathan R 1982 In Retaining Ring Failures: EPRI Workshop on Retaining Rings p. 24

Wang P C et al 1992 In Parkins symposium on fundamental aspcts of stress corrosion cracking (eds) S M Bruemmer et al (Warrendale: TMS) 399

Williams W L 1959 Corrosion 13: 539t 